\title{
Nagelaten fragmenten
}

DEEL 7 



\section{Friedrich Nietzsche}

\section{Nagelaten fragmenten}

DEEL 7: november 1887 - begin januari 1889

Teksteditie en annotatie door

Giorgio Colli en Mazzino Montinari

Vertaald door Michel van Nieuwstadt 
De vertaler ontving voor deze vertaling een werkbeurs van het Fonds voor de Letteren.

Oorspronkelijk: Band 13 van Nietzsches Sämtliche Werke. Kritische Studienausgabe in 15 Bänden. München / Berlijn / New York (Deutschen Taschenbuch Verlag/Walter de Gruyter) 1980; $1988^{2}$. Deze tekst is identiek met deel v I I van de Kritische Gesamtausgabe. Berlijn (Walter de Gruyter) 1967-1977.

Omslagontwerp en boekverzorging: Leo de Bruin, Ooij (C) 1988 by Walter de Gruyter GmbH \& Co. KG, Berlin / New York. All rights reserved

(C) Nederlandse vertaling: Uitgeverij S U N, Nijmegen 200I I S BN 906 I68 5974 NUGI 6II 